Herry Wibowo*, Prihartini Widiyanti and Syaifullah Asmiragani

\title{
The role of chondroitin sulfate to bone healing indicators and compressive strength
}

https://doi.org/10.1515/jbcpp-2020-0406

Received November 26, 2020; accepted February 21, 2021

\section{Abstract}

Objectives: The function of bone is to protect the vital organs of the body. Mechanical strength, especially compressive strength, plays an important role in fulfilling its function. Fracture healing depends on several substances, such as collagen, glucosaminoglycane and proteoglycan. Chondroitin sulfate as part of proteoglycane is an important component in the formation of callus in fracture healing. The aim of this study is to prove chondroitin sulfate role in supporting fracture healing.

Methods: The in vivo experiment has been performed to Rattus novergicus which met the inclusion criteria (age 3 months, 200-300 g weight), 18 males of $R$. norvegicus, Wistar strain, were divided into three equal groups of six rats each. After being anesthetized, fracturation was performed in a sterile manner to get simple fracture. The area of dissection is in half length of tibial bone and the fracture incision is about $1 \mathrm{~cm}$. Then it followed by immobilization of the lower leg bone on one side with a cast. The first group was given chondroitin sulfate $7 \mathrm{mg}$ in $2 \mathrm{~mL}$ distilled water/200 g weight for 2 weeks. The second group was given chondroitin sulfate $7 \mathrm{mg}$ in $2 \mathrm{~mL}$ distilled water/200 g weight for 4 weeks. The third group was given distilled water. This research was focused on treatment of cartilage. The callus position is in half length of tibial bone.

Results: There were significant differences in the increase of TGF- $\beta$, the number of osteoblasts and callus compressive strength in the groups with chondroitin sulfate treatment for 2 and 4 weeks, compared to the control group ( $\mathrm{p}<0.01)$.

\footnotetext{
*Corresponding author: Herry Wibowo, Laboratory of Physiology, Department of Biomedical, Faculty of Medicine, Universitas Surabaya, Raya Rungkut, Kalirungkut, Surabaya, 60293, Indonesia,

E-mail: drherrywibowo@staff.ubaya.ac.id

Prihartini Widiyanti, Biomedical Engineering Study Program, Department of Physics, Faculty of Science and Technology, Universitas Airlangga, Surabaya, Indonesia; and Institute of Tropical Disease, Universitas Airlangga, Surabaya, Indonesia

Syaifullah Asmiragani, Department of Orthopaedic and Traumatology, Faculty of Medicine, Universitas Brawijaya, Malang, Indonesia
}

Conclusions: Administering chondroitin sulfate in a dose of $7 \mathrm{mg}$ in $2 \mathrm{~mL}$ distilled water for 2 and 4 weeks may increase production of TGF- $\beta$, the osteoblast numbers and the callus compressive strength in fracture healing.

Keywords: callus compressive strength; chondroitin sulfate; osteoblast number; Rattus novergicus; TGF- $\beta$.

\section{Introduction}

The high number of traffic accidents in modern life results in an increasing incidence of bone fractures, the healing of which can include complications, such as malunion, delayed union and nonunion. Handling fractures cannot succeed without a full understanding of the cellular mechanisms of bone healing. There are several factors that can affect the healing of broken bones on which to base a rationalization of fracture therapy. Things which play important role in fracture healing consist of local and systemic factors. The local factors are including degree of local trauma and bone loss, type of bone affected, degree of immobilization and local pathologic conditions while the systemic factors are including age, hormones, local stress and electric currents.

One of the factors influencing healing is indicated by the presence of collagen type 1 , type 2 , type 3 , glycosaminoglycans (GAGs) and proteoglycans deposition. Heparan sulfate, dermatan sulfate and chondroitin sulfate proteoglycans are three of the important components of callus formation in the first 1-2 weeks of fracture healing $[1,2]$.

Supplementation of oral chondroitin sulfate may reduce cartilage matrix degradation process components, especially collagen II, GAGs and other proteoglycans [3, 4].

Karacal $\mathrm{N}$ et al. [5] found that chondroitin sulfate plays a role in accelerating bone healing. In this study, oral administration of chondroitin sulfate has the same effect on bone fracture healing and callus formation as local therapy directly $[3,4]$. The healing process of bone, called regeneration in fractures, is a complex process, and multifactorial. Changes that occur in fracture healing are a series of phases which include the instantaneous phase of the inflammatory reaction, the development of the osteogenic tissue formation of callus, and the soft and hard callus remodeling phase [6].

Chondroitin sulfate proteoglycans act as a major contributor in the early phase of biochemical bone healing. 
Previous research by Liang [7] on the mechanical characteristics, such as modulus of elasticity, compressive strength and tensile strength to the scaffold, found that the role of chondroitin sulfate in forming callus strength and compressive strength in vivo is an unclear mechanism. Associated with the bone healing, chondroitin sulfate appeared to accelerate the rate of bony repair [8] but did not affect the ultimate quantity or quality of bone produced. In this research, we examine the effect of chondroitin sulfate on the bone healing parameter process including the number of osteoblasts, TGF- $\beta$ and callus compressive strength. Osteoblast as bone forming cell play important role in bone healing process. TGF- $\beta$ which has physiological role in the processes of proliferation, differentiation and synthesis of cartilage and bone tissue, collectively known as the bone healing process. Callus as bony and cartilaginous material forming a connecting bridge across a bone fracture during repair is the marker of bone healing. Within 1-2 weeks after injury, a provisional callus forms, enveloping the fracture site. Callus compressive strength could illustrate the condition in fracture site whether it is leading to bone healing.

\section{Materials and methods}

Eighteen rats Rattus novergicus strain Wistar were anesthetized with ether solution using a hood and titration method. After sedation and minimal movement of the rats, hair removal was performed in the lower leg area. After showing the skin, then disinfection with povidone-iodine and narrowing the field of operation with sterile Doek. Fracturation was performed in a sterile manner, using sharp scissors to get a simple fracture, followed by immobilization of the lower leg bone on one side with a cast. Chondroitin sulfate was administered in $7 \mathrm{mg} / 200 \mathrm{~g}$ b.w./day via Nasogastric (NG) tube in the treatment groups. The duration of time for group 1 is 14,28 days for group 2 and group 3 was given a placebo in the form of a solution of $0.5 \%$ Sodium/Natrium Carboxymethyl Cellulose (CMC Na) via NG tube with a volume equal to that of the solution of chondroitin sulfate. On day 28, the rats were anesthetized with ether and 5 cc of blood taken directly from the heart. Blood samples were placed in EDTA tubes and sent to the laboratory for examination of physiology levels of TGF- $\beta$. TGF- $\beta$ levels in the control group and both treatment groups were measured by the ELISA technique. The lower leg bones containing bone callus were examined by the anatomical pathology lab, and the strength of the callus was determined using the Shimadzu Autograf. Quantifications were performed at $40 \times$ magnification to determine the number of osteoblast cells, the levels of TGF- $\beta$ in the serum were measured, and the compressive strength of the callus was measured with a three-point bending test method using a Shimadzu Autograf on the incipient fracture healing, and these values were used in a descriptive analysis. The number of osteoblasts, the levels of TGF- $\beta$ in blood serum and the callus compressive strength of each group were used to perform the statistical test, an F-test statistical analysis by ANOVA using SPSS. Significance was established based on the value of $p$ compared with $\alpha(5 \%)$. All of the research treatments in animal model has been approved by Ethical Committee of Health Research Rumah Sakit Umum Daerah Dr Saiful Anwar Malang, East Java, Indonesia with number of certificate 400/CVVIII/K.3/302/2013.

\section{Results}

The body weight of rats in all groups showed values greater than the significance level of $\mathrm{p} \geq 0.05$ meaning the data are homogeneous and appropriate for use in the research hypotheses by using a one-way ANOVA test.

\section{Levels of TGF- $\beta$}

TGF- $\beta$ levels in the control group and both treatment groups were measured by the ELISA technique. TGF- $\beta$ attachments levels measured in the control group and the groups receiving chondroitin sulfate administration for 2 and 4 weeks are shown in Figure 1.

\section{Osteoblast cell count}

The number of osteoblasts in the control group and the treatment groups receiving chondroitin sulfate for 2 and 4 weeks were analyzed histologically at $40 \times$ magnification. The number of osteoblasts for the three groups is shown in Figure 2.

\section{Compressive strength of callus}

The compressive strength of callus in the control group and both treatment groups was measured with a Shimadzu Autograf. The results for the three groups are shown in Figure 3.

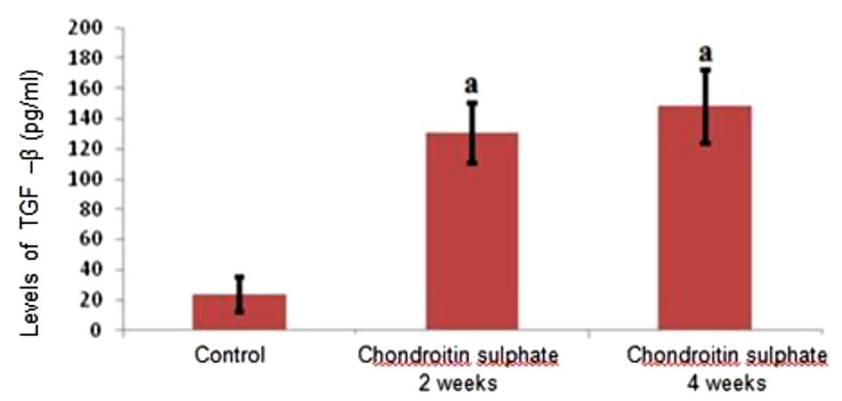

Figure 1: Diagram of stem histogram levels of TGF- $\beta$ in the control and treatment groups.

Description: $p<0.01$ compared to control group. Remarks: $\mathrm{pg} / \mathrm{mL}$ (picogram $/ \mathrm{mL}$ ). 


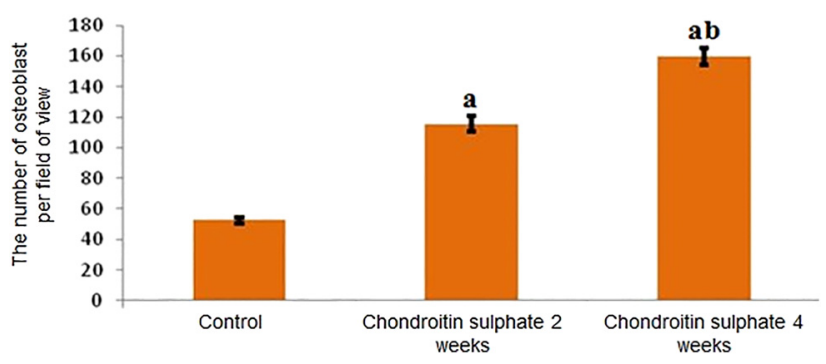

Figure 2: Diagram of the stem (histogram). The number of osteoblasts in the control and treatment groups. Description: ap<0.01 compared to control group; bp<0.01 compared to group administered chondroitin sulfate for 2 weeks.

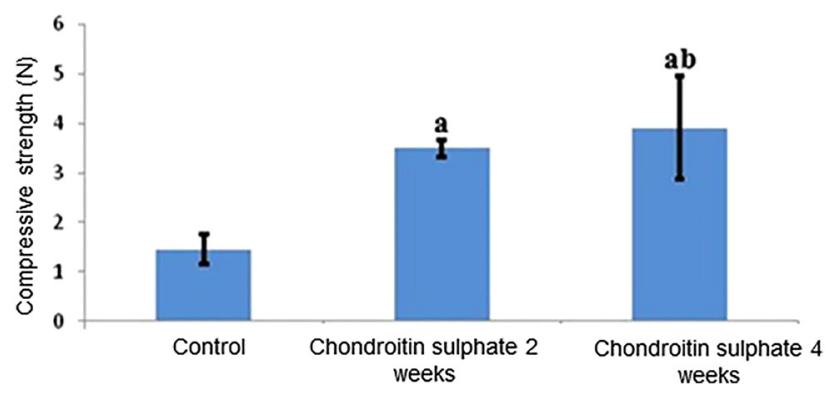

Figure 3: Diagram of the stem (histogram) compressive strength values of callus in the control and treatment groups. Description: ap $<0.01$ compared to control group; bp<0.01 compared to group treated with chondroitin sulfate for 2 weeks. Description: Newton $(\mathrm{N})$.

\section{Discussion}

Fracture healing is a complex process consisting of a variety of cellular events in a highly coordinated sequence of acute inflammation, resolution of inflammation, soft callus formation (cartilage) and hard callus (woven bone), angiogenesis, remodeling callus and laminar bone formation to bridge a gap. Woven bone supports forming the callus that bridges the fracture gap providing stability during the early healing process. Wovenbone is always remodeled and replaced by normal lamellar bone, which provides better mechanical stability [9].

TGF- $\beta$ is a molecule that is responsible for the quality of the matrix [10]. Increasing levels of TGF- $\beta$ in the treatment groups given chondroitin sulfate for 2 and 4 weeks as compared to the control group is very significant $(\mathrm{p}<0.01)$, as shown in Figure 1. This indicates that chondroitin sulfate can modulate the synthesis of TGF- $\beta$ in the fracture healing process. TGF- $\beta$ is secreted by platelets in a hematoma in the early stages by osteoblasts on intramembranous ossification, and again when the last chondrogenesis chondrocytes and endochondral ossification takes place [11]. The biological activity of chondroitin sulfate involves a variety of growth factors and chemokines, and the function is highly correlated with the sulfation pattern and characteristics of the polysaccharide chain [12]. TGF- $\beta$ is also bound by chondroitin sulfate-containing proteoglycans such as biglycan and decorin. Pathway of chondroitin in stimulating TGF- $\beta$ release through the role of decorin and biglycan which can modulate TGF- $\beta$-dependent cellular responses, apparently in a tissuespecific manner [13].

There is also evidence in the treatment groups given chondroitin sulfate of increasing osteoblasts, and this is extremely meaningful compared to the control group ( $\mathrm{p}<0.01$ ), as shown in Figure 2. This is consistent with the theory that chondroitin sulfate is involved in the adhesion of osteoblasts [14, 15]. Chondroitin sulfate is a major component of cartilage proteoglycans such as aggrecan. These proteoglycans, decorated with GAG chains, are well known for their mechanical and biological functions in articular cartilage [16].

Precursors of osteoblasts are multipotent mesenchymal stem cells such as bone marrow stromal cells, chondrocytes, muscle cells and adipocytes [17, 18]. Osteoblast progenitors not only of the original mesenchymal stromal progenitors in the marrow, but also mesenchymal cells attached to the endothelial lining of blood vessels. Osteoblast precursors reach bone from the circulation, and have an average lifespan of about 3 weeks. Osteoblasts produce and secrete matrix proteins fully differentiated from bone. Furthermore the mineralized matrix will be under the control of osteoblasts [17].

Chondroitin sulfate in both treatment groups increased the compressive strength of callus significantly compared to the control group ( $p<0.01$ ) (Figure 3). Chondroitin sulfate can stimulate proliferation and differentiation of osteoblasts involved in fracture healing. In addition, there is the possibility that chondroitin sulfate can increase the lifespan of osteoblasts $[18,19]$. Bone matrix is a mixture of fibers (fibrils of collagen type I) to withstand the force of the pull, and solid particles (hydroxyapatite crystals) to withstand compression [20]. Between the 2nd and 3rd weeks of fracture healing, callus stiffness will increase and angular displacement to the point of failure decreases. The result of this research is in accordance with the research of Schneiders W [21] which showed an increase in compressive strength by $15 \%$ by addition of chondroitin sulfate. Chondroitin sulfate is binding to the core protein through $\mathrm{N}$ - and $\mathrm{O}$-linkages leads to aggregates of monomers with high molecular weights. The proteoglycan aggregate showed viscoelastic and hydration properties [22].

Karaçal $\mathrm{N}$ et al. [5] found that chondroitin sulfate plays a role in accelerating bone healing. Therefore, 3 weeks is the time when the early healing callus formed a bridge, and 
removed cartilage [6]. In this study, the compressive strength of the callus increased when chondroitin sulfate was administered for a longer period of time ( 4 weeks). This indicates that chondroitin sulfate is capable of improving the transition of cartilage in the center of the callus into a bony callus bridge. Thus, chondroitin sulfate can accelerate mineralization and bone repair [23].

Chondroitin, better known as chondroitin sulfate, is a glycosaminoglycan (GAG) composed of a sulfated chain of branched sugars ( $\mathrm{N}$-acetylgalactosamine and glucuronic acid). It is usually found attached to proteins as part of a proteoglycan compound. A chondroitin chain can have over 100 individual sugars that can sulfated in every part of the variable. Chondroitin sulfate is an important structural component of cartilage and tissue with a constituent role in increasing resistance to stress [24]. Along with glucosamine, chondroitin sulfate is widely used as a dietary supplement to prevent osteoarthritis [25].

The oral dose of chondroitin for use in human clinical trials is $800-1,200 \mathrm{mg}$ per day. Some other sources such as shark cartilage, fish and poultry have been used. Due to chondroitin not being a uniform substance and naturally arising in many variations and forms, the composition of each supplement can differ markedly. This can be caused by supplement manufacturers not having to meet the Good Manufacturing Process (GMP) standards required for human food nor the standards for the manufacture of pharmaceuticals. No significant effects of overdoses of chondroitin have been reported for long-term use. The European League Against Rheumatism (EULAR) has confirmed that chondroitin sulfate is one of the safest drugs for osteoarthritis [26]. The provision of chondroitin sulfate for 2 or 4 weeks on healing fractures in the treatment groups was shown to increase the production of TGF- $\beta$, the number of osteoblasts and the compressive strength of the fracture healing callus.

Acknowledgments: The author delivers gratitude to Laboratory of Pharmacology, Laboratory of Physiology Faculty of Medicine, Universitas Brawijaya Malang, Laboratory of Pathology Anatomy Syaiful Anwar Hospital Malang and Basic Science Laboratory, Faculty of Pharmacy Universitas Airlangga for the facilities.

Research funding: None declared.

Author contributions: All authors have accepted responsibility for the entire content of this manuscript and approved its submission.

Competing interests: No conflict of interest. Informed consent: This research do not use human subject. There is no need to have informed consent.
Ethical approval: This research has been approved by Health Ethic Committee Saiful Anwar General Hospital Malang, East Java, Indonesia with number 400/CVVIII/ K.3/302/2013.

\section{References}

1. Song SJ, Hutmacher D, Cool SM, Nurcombe V. Temporal expression of proteoglycans in eth rat limb during bone healing. Gene 2006;379:92-100.

2. Jackson RA, McDonald M, Nurcombe V, Little D, Cool S. The use of heparan sulfate to augment fracture repair in a rat fracture model. J Orthop Res 2006;24:636-44.

3. Daniel O. Glucosamine, chondroitin sulfate, and the two in combination for painful knee osteoarthritis. N Engl J Med 2006; 354:795-808.

4. Michel BA, Stuchi G, Frey D. Chondroitins 4 and 6 sulfate in osteoarthritis of the knee: a randomized, controlled trial. Arthritis Rheum 2005;52:779-86.

5. Karaçal N, Koşucu P, Cobanglu U, Kutlu N. Effect of human amniotic fluid on bone healing. J Surg Res 2005;129:283-7.

6. Meganck JA, Begun DL, McElderry JD, Swick A, Kozloff KM, Goldstein SA, et al. Fracture healing with alendronate treatment in the $\mathrm{Brtl} /+$ mouse model of osteogenesis imperfecta. Bone 2013;56:204-12.

7. Liang WH, Kienitz BL, Penick KJ, Welter JF, Zawodzinski TA, Baskaran H. Concentrated collagen-chondroitin sulfate scaffolds for tissue engineering applications. J Biomed Mater Res 2010;94: 1050-60.

8. Moss M, Kruger GO, Reynolds DC. The effect of chondroitin sulfate on bone healing. Oral Surg Oral Med Oral Pathol 1965;20: 795-801.

9. Jurg A, Kneissel M. Bone physiology and biology. In: Smith Susan Y, Varela A, Samadfam R, editors. Bone toxicology. Switzerland: Springer International Publishing AG; 2017:33 p.

10. Nyman JS, Makowski AJ. The contribution of the extracellular matrix to the fracture resistance of bone. Curr Osteoporos Rep 2012;10:169-77.

11. Wang W, Lian N, Li L, Moss HE, Wang W, Perrien DS, et al. Atf4 regulates chondrocyte proliferation and differentiation during endochondral ossification by activating Ihh transcription. Development 2009;136:4143-53.

12. Maccari F, Ferrarini F, Volpi N. Structural characterization of chondroitin sulfat from sturgeon bone. Carbohydr Res 2005;345: 1575-80

13. Takeuchi Y, Kodama Y, Matsumoto T. Bone matrix decorin binds transforming growth factor-beta and enhances its bioactivity. J Biol Chem 1994;269:32634-8.

14. Douglas T, Heinemann S, Mietrach C, Hempel U, Bierbaum S, Scharnweber D, et al. Interactions of collagen types I and II with chondroitin sulfates $\mathrm{A}-\mathrm{C}$ and their effect on osteoblast adhesion. Biomacromolecules 2007;8:1085-92.

15. Ponik SM, Pavalko FM. Formation of focal adhesions on fibronectin promotes fluid shear stress induction of COX-2 and PGE2 release in MC3T3-E1 osteoblasts. J Appl Phys 2004;97:135-42.

16. Iozzo RV, Schaefer L. Proteoglycan form and function: a comprehensive nomenclature of proteoglycans. Matrix Biol 2015; 42:11-55. 
17. Klimczak A, Kozlowska U. Mesenchymal stromal cells and tissue-spesific progenitor cells: their role in tissue homeostasis. Stem Cell Int 2016;2016:4285215.

18. Ankrum JA, Ong JF, Karp JM. Mesenchymal stem cells: immune evasive, not immune privileged. Nat Biotechnol 2014;32: 252-60.

19. Mahla RS. Stem cells applications in regenerative medicine and disease therapeutics. Int J Cell Biol 2016;2016:6940283.

20. Tiosana D, Hochberg Z. Bone and cartilage growth and metabolism. In: Kelnar CJH, Savage MO, Saenger P, Cowell CT, editors. Growth disorders, 2nd ed. USA: CRC Press, Taylor and Francis Group; 2007:34 p.

21. Schneiders W, Reinstorf A, Pompe W, Grass R, Biewener A, Holch $M$, et al. Effect of modification of hydroxyapatite/ collagen composites with sodium citrate, phosphoserine, phosphoserine/RGD-peptide and calcium carbonate on bone remodelling. Bone 2007;40:1048-59.
22. Bali JP, Cousse H, Neuzil E. Biochemical basis of the pharmacologic action of chondroitin sulfates on the osteoarticular system. Semin Arthritis Rheum 2001;31:58-68.

23. Schneiders W, Reinstorf A, Ruhnow M, Rehberg SC, Heineck J, Hinterseher I, et al. Effect of chondroitin sulphate on material properties and bone remodeling around hydroxyapatite/collagen composites. J Biomed Mater Res 2008;8593:638-45.

24. Baeurle SA, Kiselev MG, Makarova ES, Nogovitsin EA. Effect of the counterion behavior on the frictional-compressive properties of chondroitin sulfate solutions. Polymer 2009;50:1805-13.

25. Jerosch J. Effects of glucosamine and chondroitin sulfate onCartilage metabolism in OA: outlook on other nutrient partners especially omega-3 fatty acids. Int J Rheumatol 2011;2011:969012.

26. Kloppenburg M, Kroon FPB, Blanco FJ, Doherty M, Dziedzic KS, Greibrokk E, et al. 2018 update of the EULAR recommendations for the management of hand osteoarthritis. Ann Rheum Dis 2019;78: 16-24. 


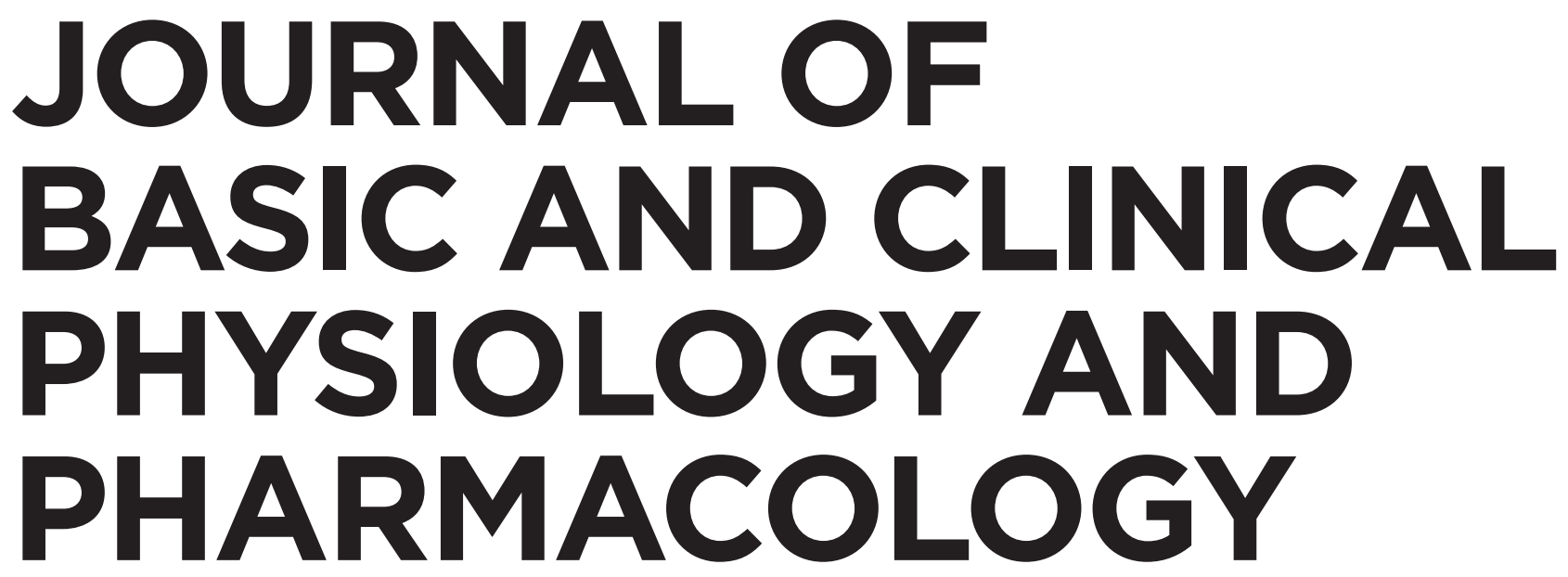

\section{EDITOR-IN-CHIEF}

Ugo Oliviero, Naples, Italy

\section{DEPUTY EDITOR}

Alberto M. Marra, Naples, Italy/Heidelberg, Germany

\section{EDITORIAL BOARD}

Giorgio Bosso, Naples, Italy

Ewelyine Biskup, Basel, Switzerland/ Shanghai, China

Pablo Demelo-Rodriguez, Madrid, Spain

Antonio Valvano, Legnano, Italy

Theodor Voisou, Bucarest, Romenia

Andrei Voisou, Bucarest, Romenia

Lorenzo Falsetti, Ancona, Italy

Valeria Raparelli, Ferrara, Italy

Ieva Ruza, Riga, Latvia

Mariarosaria De Luca, Naples, Italy

Andrea Salzano, Leicester, UK

Antonio Cittadini, Naples, Italy

Salvatore Torrisi, Catania, Italy

Leonardo Bencivenga, Naples, Italy

Gilda Varricchi, Naples, Italy

Domenico Sambataro, Catania, Italy

Raffaella Spina, Baltimora,USA

Francesca Vinchi, New York, USA,

Roberta D'Assante, Naples, Italy

\section{DE GRUYTER}


ABSTRACTED/INDEXED IN Baidu Scholar · Case · Chemical Abstracts Service (CAS): CAplus · Chemical Abstracts Service (CAS) - SciFinder · CINAHL $\cdot$ CNKI Scholar (China National Knowledge Infrastructure) $\cdot$ CNPIEC: cnpLINKer · Dimensions $\cdot$ EBSCO (relevant databases) $\cdot$ EBSCO Discovery Service · Embase · FSTA: Food Science \&amp; Technology Abstracts · Genamics JournalSeek · Google Scholar · Japan Science and Technology Agency (JST) · J-Gate · JournalGuide · JournalTOCs · KESLI-NDSL (Korean National Discovery for Science Leaders) $\cdot$ Medline $\cdot$ Meta - Microsoft Academic · MyScienceWork · Naver Academic · Naviga (Softweco) - Primo Central (ExLibris) - ProQuest (relevant databases) $\cdot$ Publons - PubMed · PubsHub · QOAM (Quality Open Access Market) · ReadCube · Reaxys · SCImago (SJR) · SCOPUS · Semantic Scholar · Sherpa/ RoMEO · Summon (ProQuest) · TDNet · Text Mining · Ulrich's Periodicals Directory/ulrichsweb · WanFang Data $\cdot$ Web of Science: Biological Abstracts; BIOSIS Previews · WorldCat (OCLC)

e-ISSN 2191-0286

All information regarding notes for contributors, subscriptions, Open access, back volumes and orders is available online at www.degruyter.com/jbcpp.

RESPONSIBLE EDITOR Prof. Ugo Oliviero, Department of Translational Medical Sciences, Federico II University, Via pansini 5, Napels, Campania, 80131 Italy, e-mail: ugo.oliviero@unina.it

PUBLISHER Walter de Gruyter GmbH, Berlin/Boston, Genthiner Straße 13, 10785 Berlin, Germany

JOURNAL MANAGER Katharina Appelt, De Gruyter, Genthiner Str. 13, 10785 Berlin, Germany, Tel.: +49 (0)30 260 05-325, e-mail: jbcpp. editorial@degruyter.com

RESPONSIBLE FOR ADVERTISEMENTS Kevin Göthling, De Gruyter, Genthiner Straße 13, 10785 Berlin, Germany, Tel.: +49 (0)30 260 05-170, e-mail: anzeigen@degruyter.com

(C) 2021 Walter de Gruyter GmbH, Berlin/Boston, Germany

TYPESETTING TNQ Technologies, Chennai, India 


\section{Write With Confidence}

\section{Journal of Basic and Clinical Physiology and Pharmacology}

\author{
COUNTRY
}

Germany

Universities and research institutions in Germany

PUBLICATION TYPE

Journals

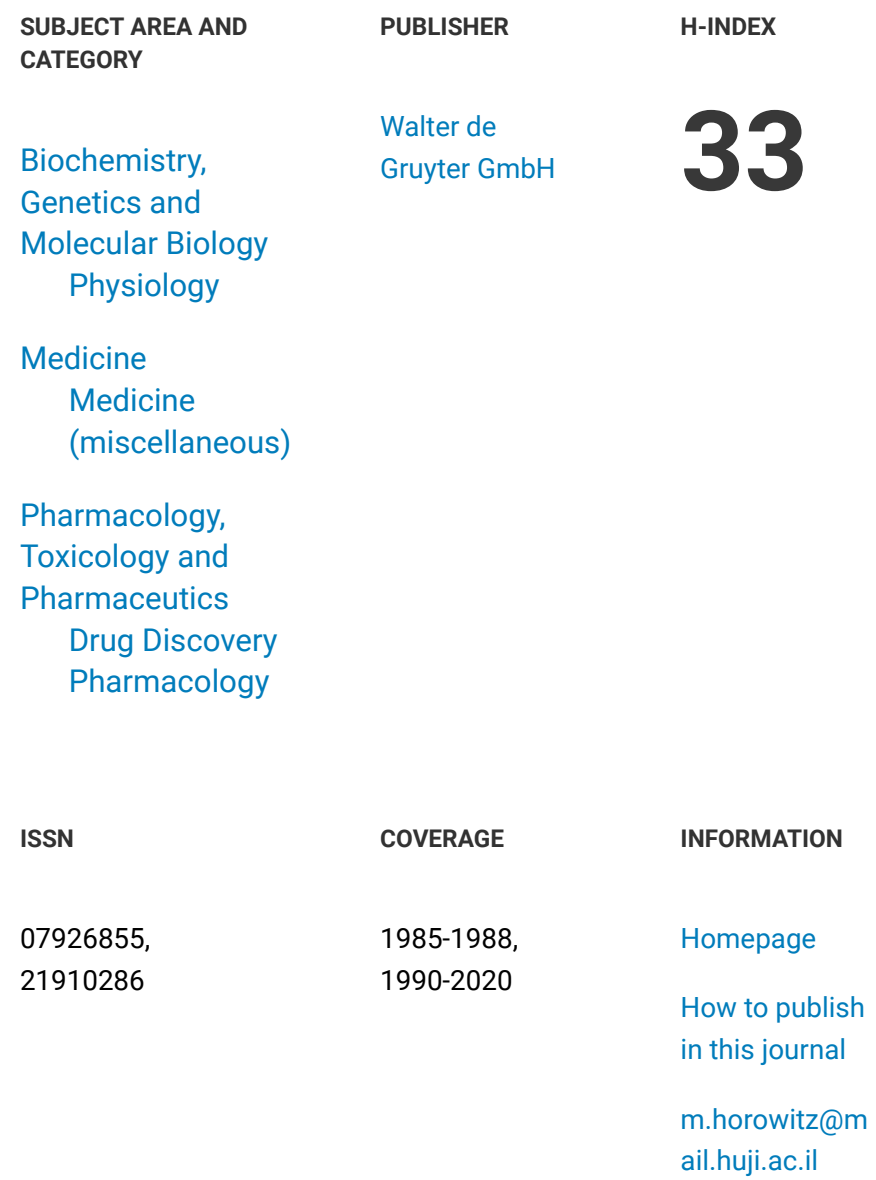

07926855

21910286

ISSN

COVERAGE

INFORMATION

1985-1988,

1990-2020

Walter de

Gruyter GmbH

H-INDEX

Homepage

How to publish in this journal

m.horowitz@m

ail.huji.ac.il 
40

20

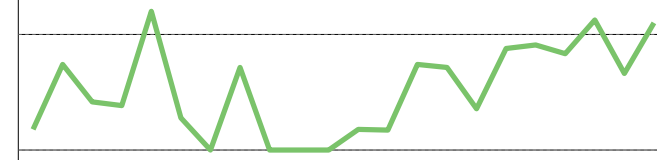

0

Cited documents Uncited documents 会困

400

200

0

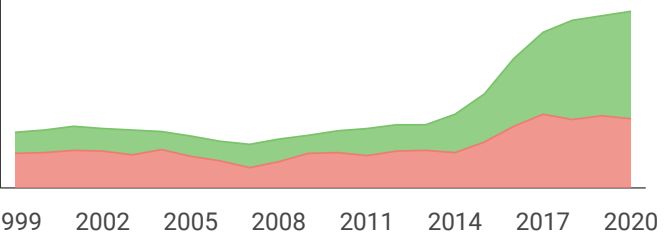

\section{G SCImago Graphica}

Explore, visually communicate and make sense of data with our new free tool.

Get it

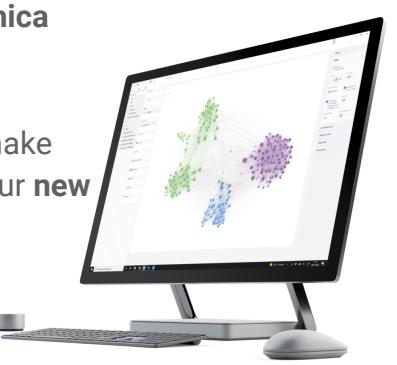

400

200

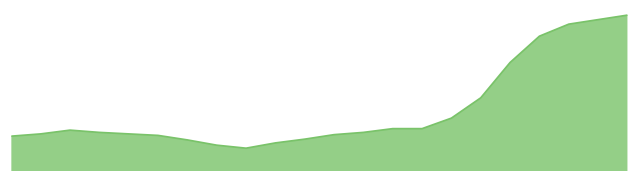

Journal of Basic and Clinical $\leftarrow$ Show this widget in Physiology and... your own website

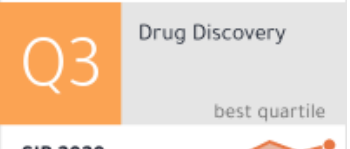

Just copy the code below and paste within your html code:

SJR 2020

0.41

$<$ a href="https://www.scimas 